\title{
THE RELATIVE VALUE OF CERTAIN DIGITALIS PREPARATIONS IN HEART FAILURE WITH AURICULAR FIBRILLATION
}

\author{
BY \\ WILLIAM EVANS \\ From the Cardiac Department of the London Hospital \\ Received December 6, 1939
}

Digitalis is given universally in heart failure with auricular fibrillation, and to prevent the recurrence of failure it is the custom to continue it. Yet there is still doubt as to the best preparations to use and the dosage to maintain adequate digitalization. In this paper a clinical assay is attempted, based on a study of subjective and objective symptoms, and the results have been controlled by comparison with less potent remedies, both within and without the digitalis group. The place of digitalis in failure with normal rhythm has long been discussed, among others by Mackenzie (1911), Lian (1926), and Luten (1936), and more recently in this department by Gavey and Parkinson (1939). Here, however, I am dealing only with patients suffering from auricular fibrillation of rheumatic origin as proved by the coincidence of mitral stenosis.

Eighteen of the 25 patients accepted as suitable remain for the complete analysis : the other 7 failed to finish the entire schedule of the investigation ; one died at another hospital, two were admitted with pulmonary infarction, two left the district and were unable to attend, while two were omitted because the heart rhythm became normal even though they were under treatment with digitalis. The 18 patients consisted of 6 men and 12 women ; their ages varied from 25 to 59, with an average of 48 years. After routine clinical examination which included electrocardiography and radiocardioscopy they were chosen as comparable cases, in that they had in common three lesions-mitral stenosis, auricular fibrillation, and heart failure.

They were treated solely as out-patients and many of them followed their usual occupation. As a rule they attended hospital fortnightly, but occasionally they returned earlier on account of fresh symptoms. A different preparation was prescribed for each test period of 14 days, but never in the same rotation. At each attendance a record was made of the patient's activities and progress during the past test period, when any symptoms of heart failure or any toxic effects were noted, and a detailed clinical and graphic examination was carried out at intervals. After a brief rest at each interview, the pulse and heart rates were counted over half-minute periods and the mean of three 
consecutive readings was accepted. Although in this way there was a record for each patient of the change in heart rate following each medicine, it was clear that the drug could not be assessed on this criterion alone. For instance, the tincture of digitalis during a period following coramine might reduce the heart rate by 50 beats a minute, while if it followed a test period on digitalis leaf the heart rate might actually rise by 10 beats. This difficulty was partially avoided by prescribing the drugs in different sequence. It was found, however, that much greater reliance could be placed on a comparison of the actual heart rate at the end of each test period, for then the influence of the preceding drug was no longer operative. Further, the extent of heart failure, determined by symptoms and by clinical and radiological examination, tallied so closely with the heart rate that this came to be accepted as a reliable index of the state of digitalization for each patient. The heart rate following different preparations may be compared in the same patient, but the rate from the same preparation is not comparable in different patients. Depression of the R-T segment in the electrocardiogram proved that digitalis was in action and to some extent indicated its hold on the heart.

The following preparations were tested : digitalis leaf, tincture of digitalis, digoxin, digitaline (Nativelle), digitaline (Allen \& Hanbury), digifoline, folinerin, strophanthin, and ouabaïne ; cardiazol and coramine were used as controls. The digitalis preparations were dispensed, in comparable doses in terms of biological assay, in some cases twice and in others three or even four times a day according to the judgment of each patient's need ; but the number of daily doses of any preparation was kept constant for each individual patient. The medicines were given for 14 days : with the one exception that cardiazol and coramine were given for 7 days only, because it was found unsafe to leave patients taking either of these drugs without medical supervision for as long as 14 days ; in reality it was digitalis they needed. Before giving an account of the results, the procedure adopted will now be instanced in one patient.

J. W., male, aged 45. Palpitation and breathlessness for several months, yet at work as a tailor until two weeks before admission when severe palpitation caused him to give it up. On examination : Rather stout. Slight cyanosis and breathlessness, increased in recumbent position. Blood pressure normal. Distension of veins of neck. Electrocardiogram, auricular fibrillation. Heart rate 164, pulse rate 124 a minute. Apex beat forcible and slightly displaced outwards. Harsh diastolic murmur in mitral area. Coarse and fine crepitations over both lung bases especially right. Liver not enlarged and no œdema of ankles. Urine trace of albumen ; daily output satisfactory. Radiogram, characteristic of mitral stenosis and heart failure. Satisfactory response to rest and digitalization during five weeks in hospital. Then referred to out-patient department and received into this series. Each medicine was given to the patient three times daily and his further progress is tabulated on the next page. 


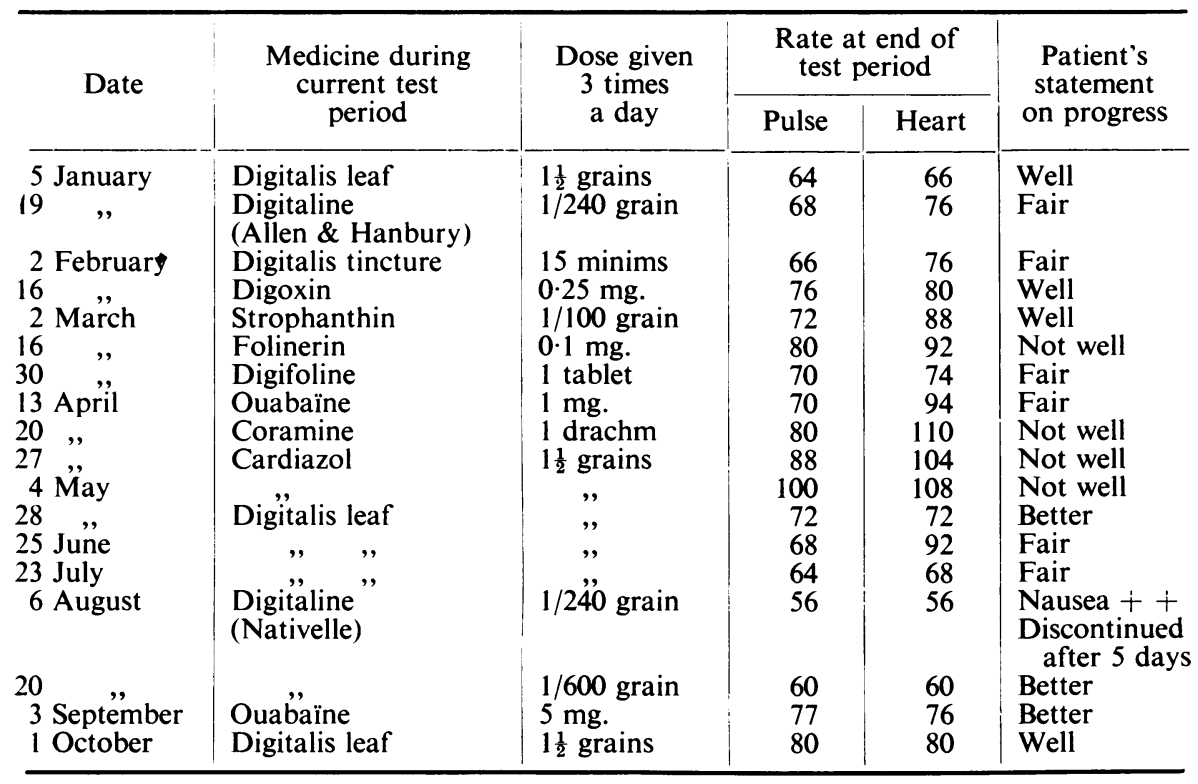

\section{RESUlTS OF OBSERVATIONS}

The results for each preparation are first given, and then the several preparations are compared. They are summarized in Tables I and II.

TABLE I

Heart Rate (Per minute) in 18 Patients with Auricular Fibrillation after TREATMENT

\begin{tabular}{|c|c|c|c|c|c|c|c|c|c|c|c|c|c|c|c|}
\hline \multicolumn{5}{|c|}{ Patient } & \multicolumn{11}{|c|}{ Preparation Used } \\
\hline 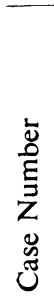 & $\stackrel{8}{<}$ & 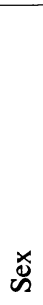 & 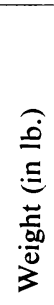 & 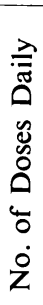 & 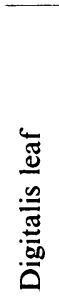 & 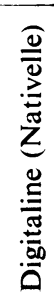 & 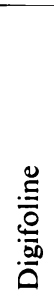 & 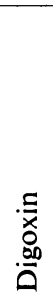 & 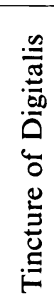 & 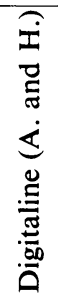 & 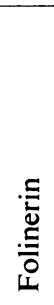 & 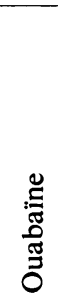 & 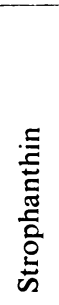 & 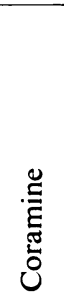 & 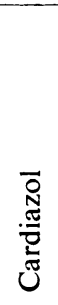 \\
\hline 1 & 55 & $\mathrm{~F}$ & 106 & 2 & 87 & 88 & 88 & 86 & 96 & 86 & 92 & 82 & 94 & 100 & 108 \\
\hline 2 & 25 & $\mathrm{~F}$ & 104 & 3 & 65 & $\begin{array}{l}\text { oo } \\
72\end{array}$ & 72 & 70 & 80 & 60 & 9 & $\begin{array}{l}02 \\
80\end{array}$ & 104 & 86 & 110 \\
\hline 3 & 56 & $F$ & 134 & 3 & 60 & 72 & 72 & 80 & 108 & 80 & 96 & 116 & 92 & 94 & 116 \\
\hline 4 & 41 & $F$ & 98 & 4 & 74 & 84 & 75 & 92 & 78 & 85 & 80 & 134 & 150 & 124 & 128 \\
\hline 5 & 49 & $F$ & 149 & 3 & 98 & 80 & 88 & 98 & 92 & 86 & 110 & 120 & 108 & 134 & 106 \\
\hline 6 & 45 & $\mathbf{M}$ & 200 & 3 & 68 & 60 & 74 & 80 & 76 & 76 & 92 & 76 & 88 & 110 & 104 \\
\hline 7 & 44 & $\mathbf{M}$ & 184 & 3 & 80 & 84 & 78 & 80 & 110 & 88 & 76 & 84 & 110 & 96 & 98 \\
\hline 8 & 65 & $F$ & 114 & 2 & 64 & 78 & 100 & 98 & 84 & 98 & 90 & 100 & 92 & 152 & 140 \\
\hline 9 & 48 & $\mathbf{M}$ & 116 & 2 & 52 & 50 & 56 & 56 & 58 & 64 & 46 & 66 & 74 & 78 & 78 \\
\hline 10 & 53 & $\mathbf{M}$ & 147 & 3 & 104 & 115 & 116 & 120 & 88 & 118 & 140 & 108 & 130 & 128 & 135 \\
\hline 11 & 51 & $\mathbf{M}$ & 135 & 3 & 70 & 46 & 62 & 66 & 90 & 68 & 104 & 80 & 84 & 114 & 96 \\
\hline 12 & 58 & $\mathrm{~F}$ & 182 & 2 & 74 & 74 & 92 & 76 & 62 & 84 & 106 & 116 & 106 & 98 & 112 \\
\hline 13 & 46 & $\mathrm{~F}$ & 84 & 2 & 52 & 62 & 72 & 64 & 72 & 84 & 100 & 124 & 130 & 100 & 130 \\
\hline 14 & 53 & $\mathrm{~F}$ & 98 & 2 & 80 & 80 & 98 & 88 & 76 & 100 & 72 & 110 & 146 & 90 & 122 \\
\hline 15 & 37 & $\mathrm{~F}$ & 104 & 3 & 74 & 80 & 78 & 94 & 106 & 94 & 88 & 94 & 90 & 96 & 126 \\
\hline 16 & 54 & $\mathrm{~F}$ & 154 & 2 & 66 & 102 & 100 & 92 & 70 & 86 & 92 & 88 & 98 & 112 & 120 \\
\hline 17 & 42 & $F$ & 185 & 2 & 84 & 88 & 70 & 77 & 96 & 96 & 98 & 92 & 104 & 104 & 150 \\
\hline 18 & 59 & $\mathbf{M}$ & 147 & 2 & 04 & 102 & 120 & 106 & 126 & 110 & 136 & 128 & 120 & 154 & 136 \\
\hline
\end{tabular}




\section{Powdered digitalis leaf}

Mackenzie (1911) chose to use either the tincture or the powdered leaf, and preference for the latter has been expressed by Wenckebach (1930), White (1931), Luten (1936), Fishberg (1937), and Gavey and Parkinson (1939).

Taking the cat unit as the minimal dose, per kilogram of cat-weight, proving lethal from slow intravenous injection of digitalis, it is estimated that $1.1 / 2$ grains of well dried and undeteriorated powdered leaf contain a single cat unit. This dose was always given as a tablet composed of pulvis digitalis folia (B.P) which is comparable with that in the United States Pharmacopœia (1936). Campbell (1938) thinks that in clinical practice digitalis leaves are stronger than when estimated from animal experiments and on the basis of clinical observations advises that tab. dig. fol. gr. i., rather than gr. 11/2, can be taken as a close equivalent of 15 minims of the tincture.

The heart rate at the end of the test periods varied from 54 to 104 a minute with an average of 75 for the 18 patients. This proved to be the lowest level obtained from any preparation tried. Similarly the powdered leaf proved its superiority when its value was based on the reduction of the rate from the preceding period. A reduction was effected in 17 patients with an average fall of 19 beats a minute, the maximum fall being 46 .

Clinical improvement was invariably produced, and nausea was only reported once.

\section{Tincture of digitalis}

Bramwell (1932) prefers standardized tincture of digitalis to any other preparation. Lewis (1934) states that as a routine the tincture should be used.

Since 15 minims of the 10 per cent. tincture represent one cat unit of digitalis, it equals $11 / 2$ grains of the powdered leaf and therefore it was prescribed in this dose.

The heart rate at the end of the test periods varied from 58 to 126 with an average of 87 beats a minute. When the change in the rate from the preceding period was studied, it was found lowered in 8 , increased in 8 , and unchanged in 2 patients. The greatest fall was 64 and the greatest rise 32 beats a minute while the average for all patients was a fall of 3 .

Clinical improvement was noted in every case. Nausea occurred in 3 patients.

\section{Digitaline (Nativelle)}

This is a glycoside derived from the leaves of the foxglove, Digitalis purpurea, and is said to be a chemical entity, constant in its physical characters and chemical reactions, and not requiring physiological standardization. It is usually dispensed as white and pink granules, the white granule containing $1 / 240$ grain $(0.25 \mathrm{mg}$.) and the pink granule $1 / 600$ grain $(0.1 \mathrm{mg}$.). Mackenzie (1911) compared the clinical effects of the tincture of digitalis with Nativelle digitaline, and found that 1/240 grain (white granule) of digitaline was equal to 
15 minims of the tincture. Campbell (1938), from clinical observations, concluded that 1/600 grain (pink granule) of Nativelle digitaline was equivalent to 15 minims of the tincture of digitalis. Stroud and Vander Veer (1937) reported on five preparations of digitalis observed over a period of six years. On comparing verodigen, a gitalin glycoside of digitalis, with digitaline (Nativelle) they found that $1 / 600$ grain of the latter produced the same clinical effects as $1 / 240$ grain of the former.

In the present series digitaline (Nativelle) was first tried in a dose of $1 / 240$ grain (white granule). Without exception it produced severe nausea and vomiting between the second and fifth day and had to be discontinued. Most of these patients reported prematurely to hospital, when the heart rate was found to be very slow; though a few returned at the end of the prescribed test period, when the rate was more rapid from the lack of digitalis therapy for eight or more days. Later it was decided always to use the pink granule containing $1 / 600$ grain.

The heart rate at the end of the test periods varied from 46 to 115 a minute with an average of 79 . When its value was based on the reduction of the rate from the preceding period, it was found lowered in 15 patients, raised in 2 , and unchanged in another. The greatest fall was 50 and the greatest rise 10 beats a minute, while the average for all the patients was a fall of 12 .

Clinical improvement was noted in every patient, and toxic symptoms were never reported from the pink granule (1/600 grain).

\section{Digitaline (Allen \& Hanbury)}

This preparation, said to consist of the active principle of the foxglove, is supplied as pink and white granules similar in appearance and dosage to those of Nativelle digitaline. For this investigation only the white granule of $1 / 240$ grain was used.

After its administration for test periods of 14 days the heart rate varied from 64 to 118 a minute, with an average of 87 . When its value was judged by the reduction of the heart rate from the preceding period, it was lowered in 7 patients, raised in 8 , and unchanged in 3 . The greatest fall was 22 and the greatest rise 24 beats a minute, while the average was a rise of 3 .

Efficient digitalization was obtained in every patient, and toxic effects were never seen.

\section{Digifoline}

This standardized preparation made by Ciba is said to contain all the therapeutically active glycosides of digitalis leaf. Each tablet is claimed to be equivalent to $11 / 2$ grains $(0 \cdot 1 \mathrm{~g}$.) of the standard digitalis leaf so this dose was used.

At the end of the test periods the heart rate varied from 56 to 115 with an average of 84 beats a minute for all the patients. When it was evaluated by the reduction of the rate from the preceding period, it was lowered in 15 patients 
raised in 2, and unchanged in another. The greatest fall was 42 , the greatest rise 10 , and the average was a fall of 15 beats a minute.

Digifoline never occasioned toxic symptoms and efficient digitalization was established in every patient.

\section{Digoxin}

Digoxin, a crystallized glycoside isolated from the leaf of Digitalis lanata, is prepared by Burroughs Wellcome and is said not to require biological standardization. Each tablet contains $0.25 \mathrm{mg}$.

The heart rate at the end of the test periods varied from 56 to 120, with an average of 85 beats a minute for all patients. When its efficiency was calculated from the reduction of the rate from the preceding period, it was found to be lowered in 10 patients, raised in 7 , and unchanged in another. The greatest fall was 36 and the greatest rise 14, while the average for all patients was a fall of 8 beats a minute.

Clinical improvement was always obtained, but anorexia was noted once.

\section{Folinerin}

Folinerin, prepared by Schering, is a crystalline glycoside obtained from the eaf of Nerium oleander, and a digitalis-like action is claimed for it. Each tablet contains $0 \cdot 1 \mathrm{mg}$.

The heart rate at the end of the test periods varied from 46 to 140, with an average of 95 beats a minute. When its value was judged by the reduction of the rate from the preceding period, it was found to have been raised in 10, lowered in 6, and was unchanged in 2 patients. The greatest rise was 38 and the greatest fall 32, while the average change was a rise of 3 beats a minute.

No toxic symptoms were observed, but noticeable clinical improvement was only recorded in 2 patients.

\section{Strophanthin}

Strophanthin, a glycoside isolated from the seed of Strophanthus kombé, is seldom used in this country for the continuous treatment of heart failure. Tablets, each containing $1 / 100$ grain, were used.

The heart rate at the end of the test periods varied from 74 to 150 beats a minute, with an average of 106 for all the patients. When the efficacy of the drug was judged by the change of rate from the preceding period, a rise had taken place in 15 patients, a fall in 2, and there was no change in 1 patient. The greatest rise was 36 beats a minute and the greatest fall 6 , while the average for all patients was a rise of 13 .

In 5 patients the symptoms of heart failure increased during the test period on strophanthin, and none showed any clinical improvement.

\section{Ouabaïne}

Ouabaïne, a strophanthin glycoside isolated from the Strophanthus gratus, has a different formula from ordinary strophanthin. Tablets containing $5 \mathrm{mg}$. (1/12 grain) were used. 
The heart rate at the end of the test periods varied from 66 to 134 beats a minute, with an average of 100 for the 18 patients. When its value was judged by the change of rate from the preceding test period, a rise was found to have taken place in every patient ; the greatest rise was 64 beats a minute and the average 22 .

Five patients complained of headache, depression, and breathlessness. Clinical improvement was not once recorded.

The results obtained with the different preparations are summarized in Table II.

TABLE II

The Change in Heart Rate in 18 Patients with Auricular Fibrillation following TREATMENT

\begin{tabular}{|c|c|c|c|c|c|}
\hline \multirow{2}{*}{ Medicine prescribed } & \multirow{2}{*}{$\begin{array}{l}\text { Average Heart } \\
\text { Rate for } 18 \\
\text { patients at } \\
\text { end of test } \\
\text { periods }\end{array}$} & \multicolumn{3}{|c|}{$\begin{array}{c}\text { Number of Patients where the Heart } \\
\text { Rate was }\end{array}$} & \multirow{2}{*}{$\begin{array}{l}\text { Net } \\
\text { average of } \\
\text { Change of } \\
\text { Heart Rate }\end{array}$} \\
\hline & & Lowered & Unchanged & Raised & \\
\hline $\begin{array}{l}\text { Digitalis leaf } \\
\text { Digitaline } \\
\text { (Nativelle) }\end{array}$ & $\begin{array}{l}75 \\
79\end{array}$ & $\begin{array}{ll}17 & (20)^{*} \\
15 & (15)\end{array}$ & $\begin{array}{l}0 \\
1\end{array}$ & $\begin{array}{ll}1 & (2)^{*} \\
2 & (8)\end{array}$ & $\begin{array}{l}-19 \\
-12\end{array}$ \\
\hline $\begin{array}{l}\text { Digifoline } \\
\text { Digoxin } \\
\text { Tincture of digitalis } \\
\text { Digitaline } \\
\text { (Allen\&Hanbury) }\end{array}$ & $\begin{array}{l}84 \\
85 \\
87 \\
87\end{array}$ & $\begin{array}{rr}15 & (19) \\
10 & (19) \\
8 & (24) \\
7 & (6)\end{array}$ & $\begin{array}{l}1 \\
1 \\
2 \\
3\end{array}$ & $\begin{array}{lr}2 & (6) \\
7 & (6) \\
8 & (16) \\
8 & (14)\end{array}$ & $\begin{array}{r}-15 \\
-8 \\
-3 \\
+3\end{array}$ \\
\hline $\begin{array}{l}\text { Folinerin } \\
\text { Ouabaïne } \\
\text { Strophanthin }\end{array}$ & $\begin{array}{r}95 \\
100 \\
106\end{array}$ & $\begin{array}{ll}6 & (14) \\
0 & - \\
2 & (4)\end{array}$ & $\begin{array}{l}2 \\
1 \\
1\end{array}$ & $\begin{array}{ll}10 & (14) \\
17 & (23) \\
15 & (16)\end{array}$ & $\begin{array}{r}+3 \\
+22 \\
+13\end{array}$ \\
\hline $\begin{array}{l}\text { Coramine } \\
\text { Cardiazol }\end{array}$ & $\begin{array}{l}109 \\
117\end{array}$ & $\begin{array}{ll}0 & - \\
1 & (8)\end{array}$ & $\begin{array}{l}2 \\
2\end{array}$ & $\begin{array}{ll}16 & (26) \\
15 & (23)\end{array}$ & $\begin{array}{l}+21 \\
+19\end{array}$ \\
\hline
\end{tabular}

* The figures in brackets show the average reduction or rise, in beats per minute.

\section{Cardiazol}

Cardiazol or metrazol has a formula related to camphor, and by some it has been acclaimed as a "heart stimulant" that reduces the heart rate and increases the venous flow, coronary flow, and the cardiac output. Cardiazol was tested, not in the belief that it possesses a digitalis-like action, but rather as a comparison with the other drugs. It was given orally as tablets containing $11 / 2$ grains $(0 \cdot 1 \mathrm{~g}$.), but the test period of 14 days was reduced to 7 for it became evident after trial that it was unsafe to withhold digitalis from patients in this series for longer than a week.

The heart rate at the end of the test periods varied from 78 to 150 beats a minute, with an average of 117 for the series. When its value was estimated from the change of rate from the preceding period, there was a rise in 16 patients. The greatest rise was 48 beats a minute and the average 19 .

Breathlessness, palpitation, weakness, and headache, appeared in 9 patients, and clinical improvement was not once recorded. 


\section{Coramine}

Coramine, reputed to be a "cardiac stimulant," is widely used. It was given orally to each patient in this series in the optimum dose of 30 minims ( 2 c.c.) ; but, like cardiazol, it was included more as a control than for its alleged value. As with cardiazol, it was found unsafe to allow patients taking it to be without medical supervision for more than 7 days, by which time the lack of digitalis had become evident.

The heart rate at the end of the shorter test periods varied from 78 to 154 beats a minute, with an average of 109 for all patients. When its value was judged by the change of the rate from the preceding period, a rise was recorded in every case. The greatest rise was 62 beats a minute and the average 21 .

Headache was distressing in 7 patients and clinical improvement was not once recorded. In 15 patients the symptoms of heart failure reappeared during its administration.

The shorter test period adopted for cardiazol and coramine has to be taken into account when comparing their influence on the heart rate and their clinical effects with those of digitalis preparations, because the recorded rates would be much higher after the standard and longer test period and the symptoms of heart failure correspondingly greater.

\section{DiscuSSION OF RESULTS}

The scarcity of controlled observations on the clinical effects of various digitalis preparations prompted this inquiry into their relative value. Mackenzie (1911) compared the effects of the tincture with Nativelle digitaline and a pill containing powdered digitalis leaf, squills, and mercury. He watched for the first sign of a digitalis reaction and then noted the quantity of the drug which had induced it. In 1925 Cushny deprecated the fact that even though many preparations were employed, little had been done in the way of accurate comparison of their effects in man. Luten (1936) stated that on the basis of both animal experiments and clinical experience there was no valid reason for preferring one particular digitalis preparation to another on the grounds of some alleged selectivity of action on the heart.

The right choice of a preparation and of dosage will not be decided from experiment in animals, but from such comparison in patients as is attempted in the present investigation. When judged by amelioration of failure symptoms, freedom from toxic effects, and decrease in the heart rate, 6 of the 11 preparations tried proved satisfactory. Arranged in the order of therapeutic efficiency when used in customary doses, they were : powdered digitalis leaf, digitaline (Nativelle), digifoline, digoxin, tincture of digitalis, and digitaline (Allen \& Hanbury). Three preparations, folinerin, ouabaïne, and strophanthin, never produced satisfactory digitalization, and their routine use in patients with heart failure is unjustified. As to cardiazol and coramine, which served to control the observations on the other drugs tried, it was not expected that either would reduce the heart rate or master the symptoms of failure, but it was. 
surprising to find that, apart from not benefiting a single patient, they induced ill effects so frequently. It is clear that neither cardiazol nor coramine have any place in the continuous treatment of heart failure. The comparison is well shown in Fig. 1, which also indicates the cost of treatment and shows that the more effective preparations are not the more expensive ones.

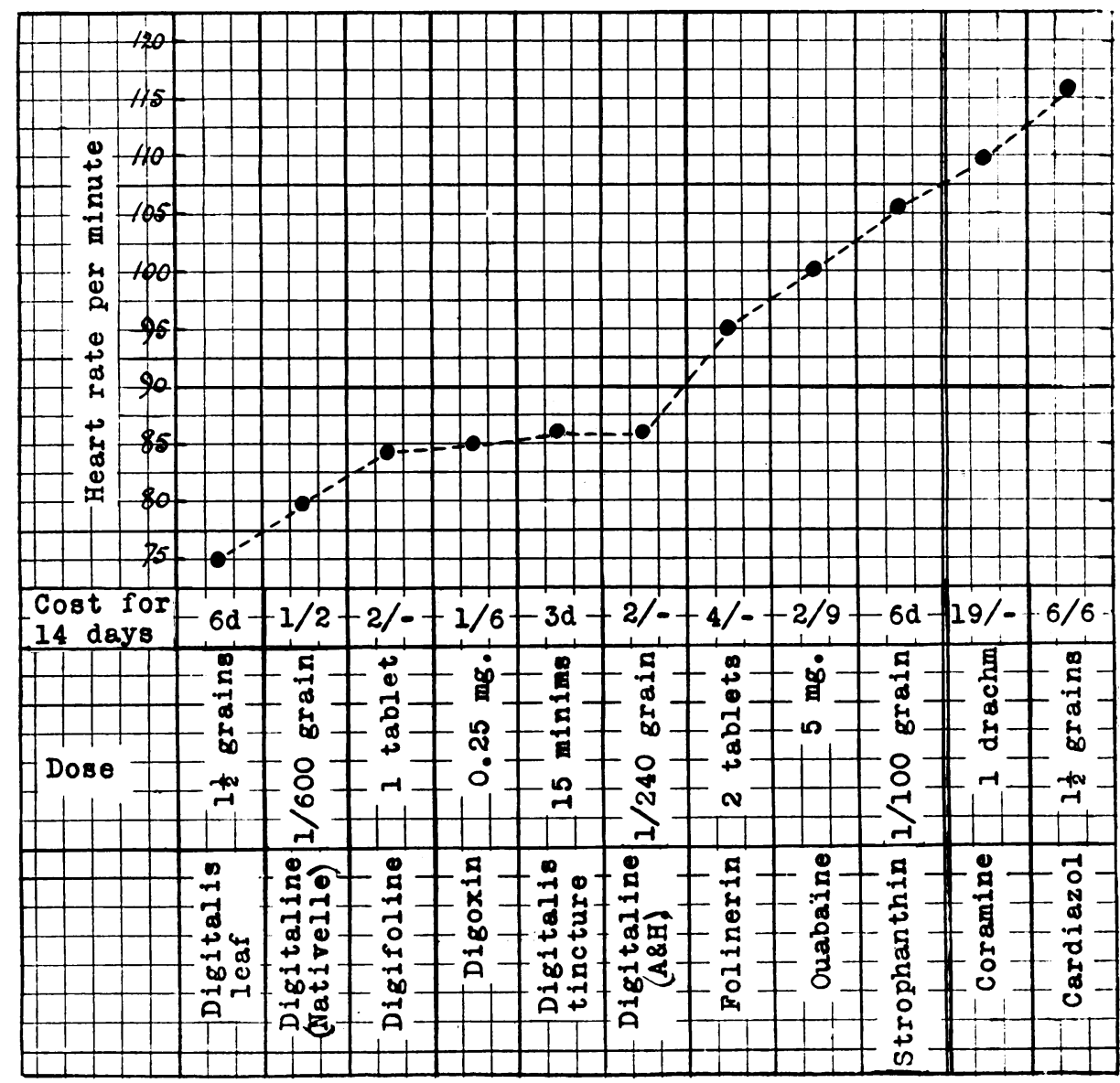

Fig. 1.-The effect of drugs on the heart rate in 18 patients with auricular fibrillation. An average rate of 90 has been accepted as the uppermost level of satisfactory digitalization for this series. The cost of each drug is quoted, for hospital patients receiving it three times a day for a fortnight. Drugs to the left of the upright double line were given over periods of 14 days ; those to the right, over periods of 7 days.

The dosage of digitalis for ensuring adequate digitalization has long been in dispute, but most authorities think that it must be determined separately in each patient. Withering's (1785) opinion was that digitalis should be continued until it acted on the kidneys, stomach, pulse, or bowels, when it should be stopped. Mackenzie (1911) said that patients instructed on the symptoms indicating a sufficiency of the drug could generally help thereby to decide the dosage that suited them. Eggleston (1915 and 1920) devised a formula for 
estimating the amount of digitalis required to produce a state of digitalization, founded on the body weight and the amount of digitalis preparation to one cat unit.

In a clinical investigation of digitalis action, Lyon and Gilchrist (1927) found wide variation in the effects of uniform doses as calculated from the body weight. Baker and Bloom (1936) found that the experimental cat unit was not a reliable index of the proper clinical dosage, nor could this be determined in patients by means of Eggleston's formula. Luten (1936) said that the optimum dose of digitalis, whether for the induction of its effects or for its maintenance, should be judged individually; and he urged that no patient should receive an arbitrary dose in an attempt to bring about some anticipated effect, but rather that the effect produced must always determine the dosage.

This investigation has confirmed the view that the dosage of digitalis cannot be predicted for each patient and that it can only be settled after clinical trial. Evidence is produced that it is not possible to calculate the appropriate clinical dose of any digitalis preparation from biological standardization, nor yet from the patient's body weight. Thus digitalization of a patient of heavy weight was sometimes maintained by small doses of digitalis, while that of a patient of light weight was often only reached by larger doses (see Table I).

Throughout the investigation the single dose of each preparation was kept constant, as was the daily dose for an individual patient, but all did not receive an identical amount, and the decision on this had to be taken in each case after a preliminary clinical trial. Thus for powdered digitalis leaf a dose of $11 / 2$ grains was always prescribed, but the daily dose was twice a day in 9 patients, three times a day in 8 , and four times a day in 1 patient.

The fallacy of deducing the value of a digitalis preparation from a comparison of its effect upon heart rate in different patients became more apparent as the investigation proceeded. True evaluation must therefore depend on a comparison of the heart rate after treatment with different preparations in the same patient. In fact, the heart rate during successful digitalization differs widely among patients with auricular fibrillation (see Table I). In one a satisfactory rate was 115 , but in another 52 beat a minute, directing our greater attention to the abatement of failure symptoms and the reduction of the pulse deficit as the indications of improvement.

In this country four manufacturing chemists supply digitaline granules that are similar in colour and dosage to those prepared by Nativelle. Although the dosage is the same, the therapeutic effect may differ greatly ; and certainly of the two brands tested in this investigation, Nativelle digitaline produced digitalis benefit that was twice as great as that gained from Allen and Hanbury's digitaline. One must, therefore, know which product is being used, so that an appropriate amount may be ordered.

\section{CONCLUSIONS}

The effects of six preparations of digitalis and of three others with a digitalis-like action were watched in eighteen comparable cases of auricular 
fibrillation with mitral stenosis and heart failure. Each preparation was tried in every patient, and its value was assessed at the end of test periods of fourteen days, with due regard to the heart rate, pulse deficit, failure symptoms, toxic effects, and electrocardiographic changes. The observations were controlled by introducing test periods during which digitalis was not given in any form and cardiazol or coramine were the only drugs prescribed. The following conclusions were reached :

1. Efficient digitalization was always induced and maintained by powdered digitalis leaf, digitaline (Nativelle), digifoline, digoxin, tincture of digitalis, and digitaline (Allen \& Hanbury), mentioned in the order of their therapeutic activity in customary doses and from a practical standpoint.

2. Powdered digitalis leaf proved to be the best preparation for maintaining equable digitalization. It was also one of the cheaper preparations.

3. Digitaline (Nativelle) in a dose of $1 / 600$ grain (pink granule) showed greater digitalis effect than digitaline (Allen \& Hanbury) in a dose of $1 / 240$ grain (white granule). Digitaline (Nativelle) in a dose of 1/240 grain (white granule) proved too potent for continuous use.

4. Folinerin, ouabaïne, and strophanthin (orally) failed to produce adequate digitalization and their routine use in heart failure is not justified.

5. Symptoms of heart failure developed in every patient when either cardiazol or coramine was prescribed without digitalis.

6. The actual heart rate was found to be an unreliable index of successful digitalization; thus for one patient it was 115 during a period of maintained clinical improvement and for another 52 beats a minute. The heart rate gains the greatest significance when the digitalis effect of different preparations is estimated in the same patient. Freedom from symptoms and signs of heart failure served best to indicate successful digitalization.

7. It proved a good custom to adopt a standard dose for each digitalis preparation and to vary only the total daily dosage. Thus with powdered digitalis leaf, the single dose of $11 / 2$ grains was always employed, but this was given either twice, three times, or four times a day, according to need.

8. The optimal dose of digitalis could not be predicted with any accuracy, and it had to be sought by trial and error, thus implying a therapeutic study in every patient.

This investigation was carried out during the tenure of a grant from the Medical Research Council. I wish to acknowledge help from Dr. Owen Loughnan, working under the direction of Professor Arthur Ellis and holding a grant from the Medical Research Council of Ireland. Dr. John Parkinson has helped me with advice and criticism.

\section{REFERENCES}

Baker, J. P. and Bloom, N. (1936). Ann. intern. Med., 10, 605.

Bramwell, C. (1932). Heart Disease, London.

Campbell, M. (1938). Guy's Hosp. Gazette, 52, 177.

Cushny, A. R. (1925). Digitalis and its Allies, London.

Eggleston, C. (1915), Arch. intern. Med., 16, 1.

- (1920). J. Amer. med. Ass., 74, 733.

Fishberg, A. M. (1937). Heart Failure, London.

Gavey, C. J. and Parkinson, J. (1939). Brit. Heart J., 1, 27. 
Lewis, T. (1934). Diseases of the Heart, London.

Lian, C. (1926). Traité de Pathologie Médicale, 4, 2nd ed., Paris.

Luten, D. (1936). The Clinical Use of Digitalis, Illinois.

Lyon, D. M. and Gilchrist, A. R. (1927). Edin. med. Jour., 34, 594.

Mackenzie, J. (1911). Heart, 2, 273.

Stroud, W. D. and Vander Veer, J. B. (1937). J. Amer. med. Ass., 109, 1808

Wenckebach, K. F. (1930). Brit. med. J:, 1, 181.

White, P. D. (1931). Heart Disease. New York.

Withering, W. (1785). An Account of the Foxglove, etc., Birmingham. 